\title{
ABDOMINAL ULTRASONOGRAPHY IN CATTLE
}

\author{
Munday, K. ${ }^{1}$, Mudron P. ${ }^{2}$ \\ ${ }^{1}$ Prings Farmhouse, Prings Lane, Maplehurst, Rh13 6GZ \\ England \\ ${ }^{2}$ Clinic of Ruminants, University of Veterinary Medicine and Pharmacy \\ Komenskeho 73, 04181 Košice \\ The Slovak Republic \\ pavol.mudron@uvlf.sk
}

\section{ABSTRACT}

The main goal of this study was to design and propose specific abdominal zones that would contain the gastrointestinal organs in healthy cattle when scanned with trans-abdominal ultrasound. The second goal was to measure the intestinal wall thicknesses of the cranial duodenum, jejunum and colon and to compare healthy cattle intestinal wall thicknesses with pathological cases. All of the six healthy cattle had organs located in the zones proposed. Three of the four pathological cases had organs outside of the zones proposed. The six healthy cattle had an average cranial duodenum wall thickness of $2.45 \mathrm{~mm}$, an average jejunum wall thickness of $1.90 \mathrm{~mm}$ and an average colon wall thickness of $3.02 \mathrm{~mm}$. Of the pathological cases, three out of four had intestinal walls that were thicker than that of the average values for the healthy cattle. The thickest intestinal walls were found in the paratuberculosis positive cow. This cow had a cranial duodenum wall thickness of $9.5 \mathrm{~mm}$, a jejunum wall thickness of $4.9 \mathrm{~mm}$ and a colon wall thickness of $10.0 \mathrm{~mm}$. In conclusion, trans-abdominal ultrasonogra-
\end{abstract}

phy has the potential to be an ideal diagnostic tool for the investigation of the bovine gastrointestinal tract and gastrointestinal disorders such as abscesses, peritonitis and displacement of the abomasum. Trans-abdominal ultrasound also has the potential to be a non-painful, non-invasive tool for the diagnosis of proliferative intestinal inflammations in cattle.

Key words: cattle; intestines; paratuberculosis; ultrasonography

\section{INTRODUCTION}

Ultrasonography has mainly been used in bovine veterinary medicine in the field of reproduction and lameness. The use of trans-abdominal ultrasound to examine the gastrointestinal tract has been studied to a lesser extent. Initial studies have used ultrasound to evaluate the normal anatomical position and the size of the abdominal organs in cattle with a focus on reticulum anatomy, physiology, and pathology [4]. Other studies have involved using ultra- 
sound as a tool for diagnosing abdominal and gastrointestinal disorders such as peritonitis, left and right displaced abomasum, abscesses and ileus [2]. Currently, no studies have been published using ultrasound as a technique for diagnosing Mycobacterium avium subsp. paratuberculosis (Johne's disease) in cattle. Previous studies have used ultrasound to study Mycobacterium avium subsp. paratuberculosis in camels and goats [10]. Ultrasound may provide the opportunity to establish a diagnosis and sometimes a prognosis of abdominal disorders and can be used to monitor the progression of therapy of some of the major diseases encountered in a bovine practice. Ultrasound allows a "cow-side" diagnosis and can reduce time and money for the producer and spare pain for the animal [3].

The main goal of this study was to design and propose specific abdominal zones that would contain certain gastrointestinal organs in healthy cattle when scanned with trans-abdominal ultrasound. In addition, the study was designed to measure the thickness of the cranial duodenum, jejunum and colon walls.

\section{METHODS AND MATERIALS}

In this study, six healthy $500-600 \mathrm{~kg}$ Holstein $\times$ Friesian cattle were examined trans-abdominally with ultrasound. Four pathological cases were scanned, which were; left displaced abomasum (LDA), paratuberculosis, a cow post percutaneous abomasopexy and local peritonitis. The ultrasonographic examinations were performed on non-sedated, standing cattle using a $3.5-5.0 \mathrm{MHz}$ convex transducer (SonoScape A5V) and was mainly focused on the examination of peritoneum, abomasum, duodenum, jejunum, and colon. The paratuberculosis in patient 2 , was diagnosed according to history, clinical signs and positive results of blood examination by PCR [8].

The abdominal zones were designed to be able to easily identify the abdominal organs and their locations and to help in the diagnosis of pathological cases. The determination of the designed zones were based on bovine morphology in healthy animals [9]. Zone one (Fig. 1) is the left side of the abdomen, from the tuber coxae to the 6-8th intercostal space (ICS). The rumen and reticulum are located in this zone. Zone two is split into zone $2 \mathrm{~L}$ and zone $2 \mathrm{R}$ (left and right side of the sternum). Zone two is located on the left and right side of the sternum in the ventral third of the abdomen from the 6-9th ICS. The dorsal border of zone $2 \mathrm{~L}$ and $2 \mathrm{R}$ is at the level of the olecranon and the ventral border is the base of the abdomen. The reticulum is located within zone $2 \mathrm{~L}$ and zone $2 \mathrm{R}$. Zone three is located on the right side of the abdomen. Its dorsal border is at the level of ten $\mathrm{cm}$ over the olecranon and the ventral border is at the level of the olecranon. Zone three runs from the 7-10th ICS. The omasum is located within zone three. Zone four is the area $10 \mathrm{~cm}$ caudal to the xyphoid process of the sternum and to the right paramedian region of the ventral midline to the level of the umbilicus. The dorsal border of this zone is the level of the olecranon and the ventral border is the bottom of the abdomen. Zone four contains the majority of the abomasum, pylorus and part of the cranial duodenum. Zone five is located in the dorsal half of the abdomen. The dorsal border of zone five is processus transversus of the

Table 1. Thickness of intestinal walls $(\mathrm{mm})$ in the control cattle (mean \pm SD) and four pathological cases

\begin{tabular}{lccc}
\hline \multicolumn{1}{c}{ Animal } & Cranial Duodenum & Jejunum & Colon \\
\hline Control cattle $(\mathrm{n}=6)$ & $2.45 \pm 1.19$ & $1.9 \pm 0.4$ & $3.02 \pm 0.58^{*}$ \\
Patient 1 (LDA) & 6.1 & 2.8 & 7 \\
Patient 2 (paratuberculosis) & 9.5 & 4.9 & 10 \\
Patient 3 (post abomasopexy) & 5.5 & 2.2 & 7 \\
Patient 4 (peritonitis) & 1.8 & 1.4 & 2.1 \\
\hline
\end{tabular}

* _ Colon differs from jejunum $(P<0.01)$ 


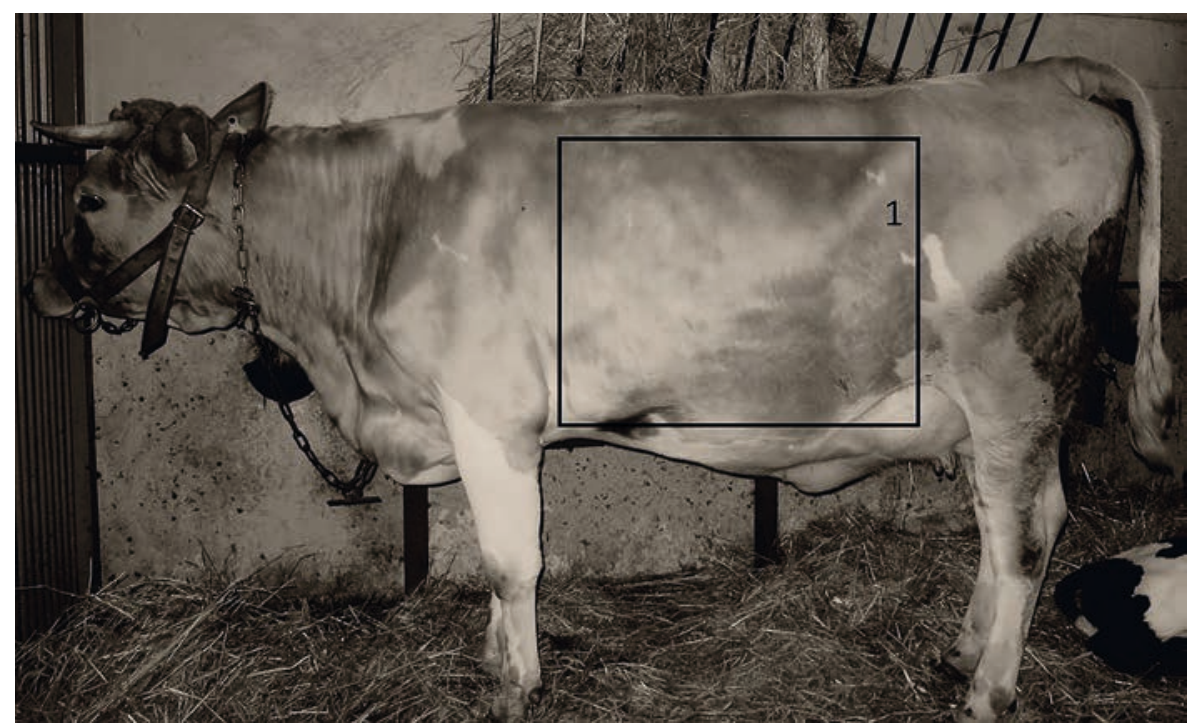

Fig. 1. Zone one (left abdomen: reticulum and rumen)

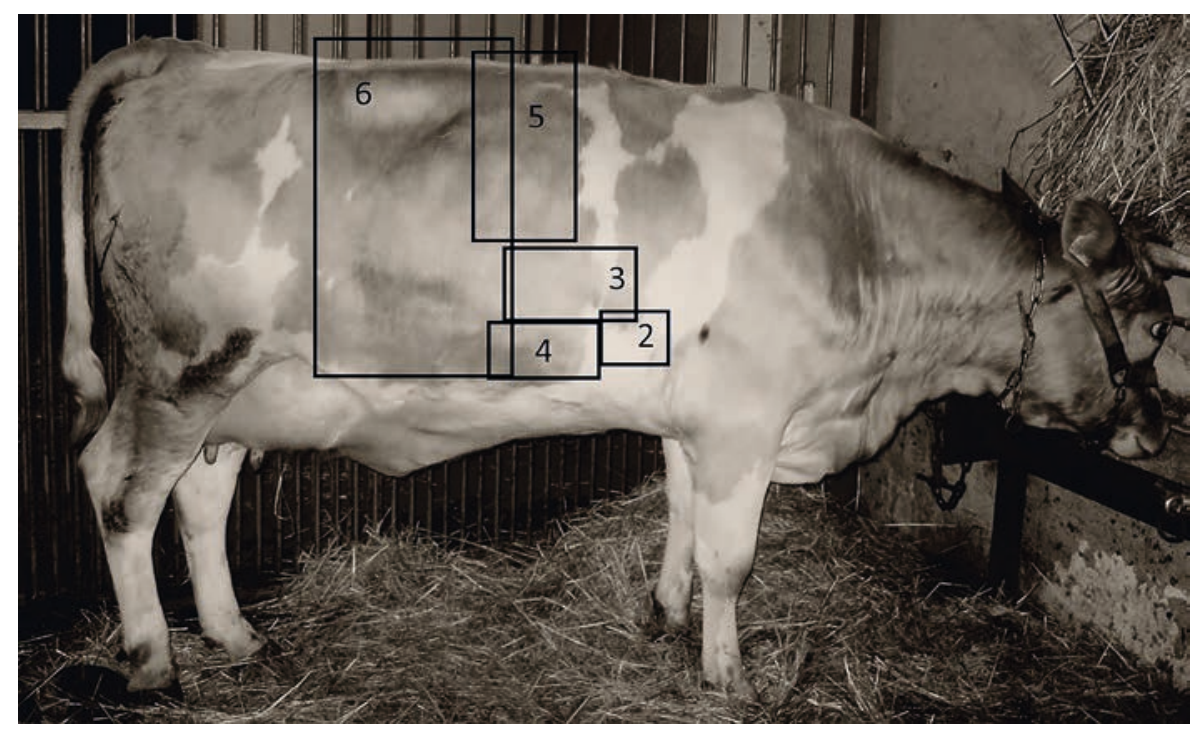

Fig. 2. Zones 2-6 (right abdomen: reticulum, omasum, abomasum, duodenum, jejunum, and colon)

thoracic vertebrae and the ventral border is at the level of the articulatio humeri. Zone five is located from the $10-$ 12th ICS. The liver and cranial portion of the duodenum is located in zone 5. Zone six is divided into 3 subzones; $6 \mathrm{~A}, 6 \mathrm{~B}$ and $6 \mathrm{C}$. Zone six extends from the 10th ICS to the tuber coxae. The dorsal border of zone $6 \mathrm{~A}$ is the processus transversus of the lumbar veterbrae, the ventral border is at the level of the articulation humeri. Zone $6 \mathrm{~A}$ contains the colon. The dorsal border of zone $6 \mathrm{~B}$ is at the level of the articulation humeri and the ventral border is at the level of the articulation cubiti. Zone $6 \mathrm{~B}$ contains loops of the jeju- num and the parts of the colon may be visualised. The dorsal border of zone $6 \mathrm{C}$ is at the level of the articulation cubiti and continues ventrally to the linea alba. Within zone 6C, loops of the jejunum can be imaged (Fig. 2).

The intestinal dimensions and intestinal wall thicknesses were measured within the ultrasound examination after scan freezing.

The differences in the wall thicknesses among the duodenum, jejunum, and colon were statistically analysed by an unpaired $t$-test. The level of significance was set at $\mathrm{P}<0.01$. 


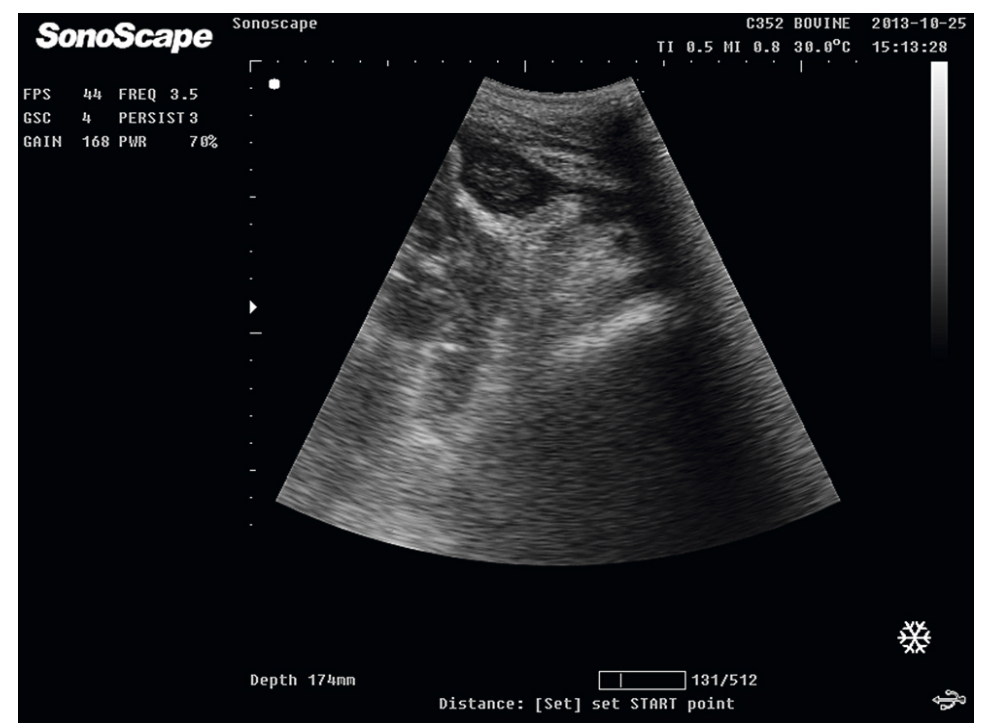

Fig. 3. Ultrasound of zone four in patient 3 with post abomasopexy complications. Abscess cranial to the umbilicus and thickening of the abomasal wall are visible. The abscess measured $19.3 \times 37.7 \mathrm{~mm}$

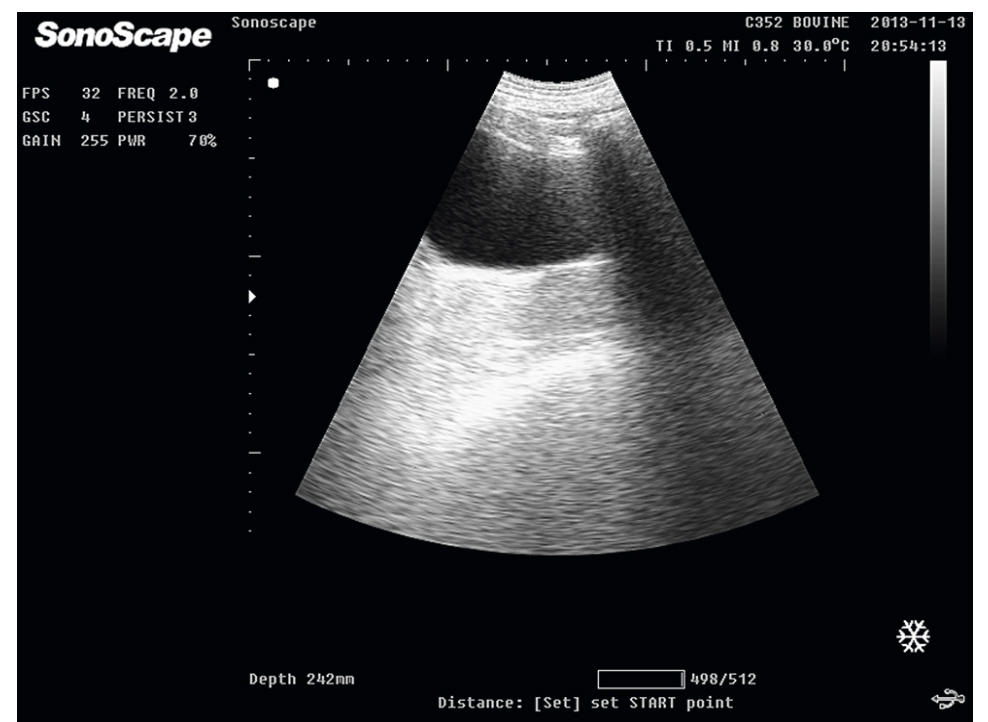

Fig. 4. Ultrasound of the hypoechogenic pocket of fluid within the abdominal cavity at the 9-10th ICS

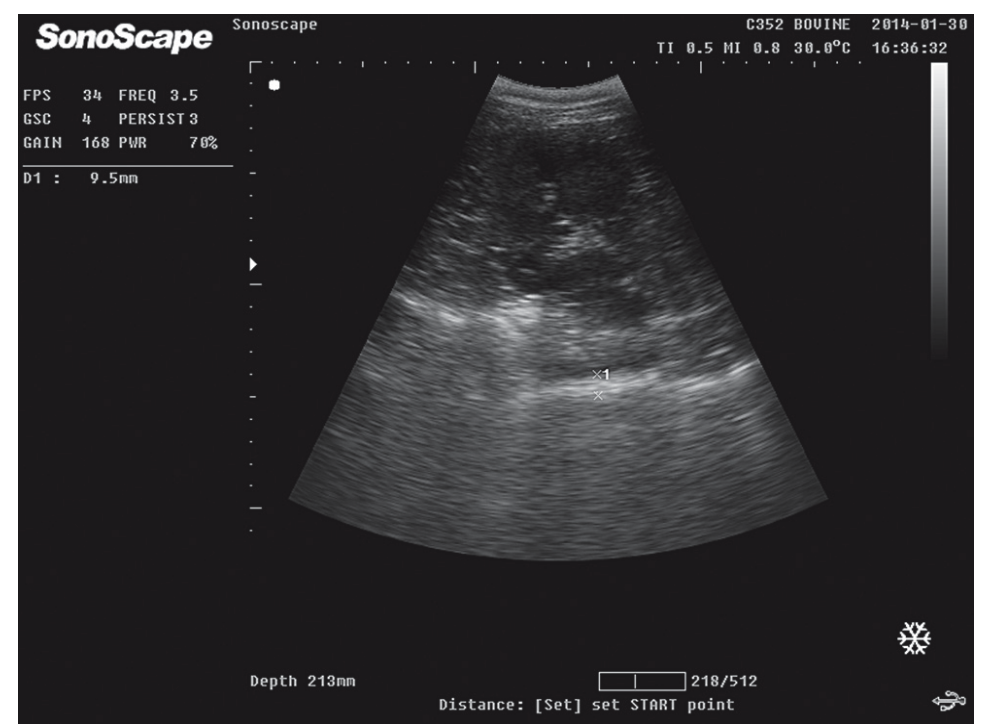

Fig. 5. Ultrasound of the cranial duodenum wall thickness (white line with two $x$ ) located in zone five of patient 2 


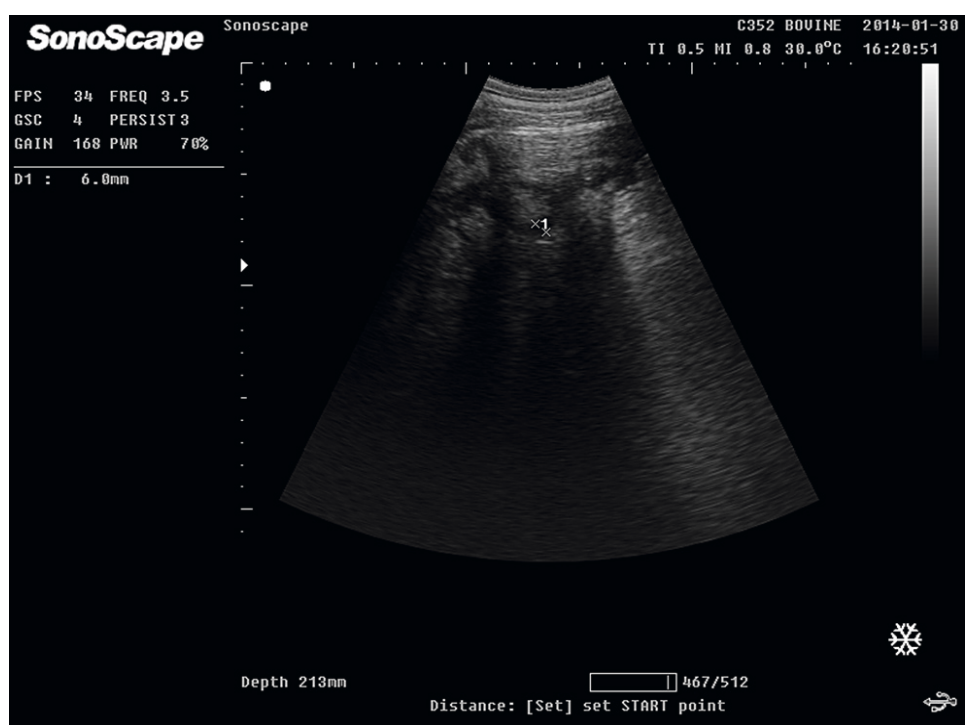

Fig. 6. Ultrasound of the jejunum wall thickness (dark line with $2 \times$ ) imaged in a more cranial location than normal, at the level of the 8th ICS in zone 4 , as well as zone $6 \mathrm{~B}$ and $6 \mathrm{C}$

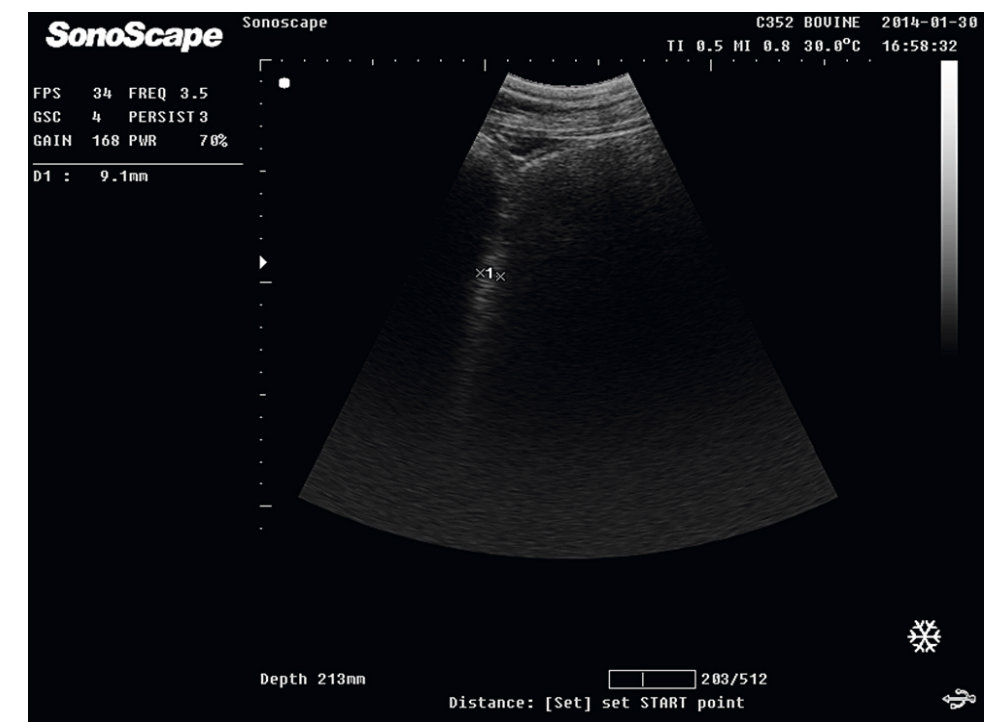

Fig. 7. Ultrasound of the colon wall thickness (light line with two $\times$ ) imaged in zone $6 \mathrm{C}$ of patient 2

\section{RESULTS}

All of the proposed zones were scanned in each animal. All six healthy cattle had their organs located in the specific zones proposed. Only patient 3 , post abomasopexy had all the organs within the proposed zones. All the other pathological cases had their organs outside the described abdominal zones.

Patient 1 had LDA and its abomasum was imaged in zone one at the 11-12th ICS. All the other abdominal organs were displaced cranially and ventrally across the right abdomen due to the dilation and displacement of the abomasum to the left. Patient 2 was positive for paratuberculosis. Ultrasound was performed and it was found that the jejunum was in a more cranial position than normal. It was imaged in zone three at the 8-9th ICS. The ultrasound of patient 3, after abomasopexy surgery, revealed all of their organs to be within the zones previously proposed. The ultrasound of this patient also revealed an abscess located caudally to the fixation site, and cranially to the umbilicus (Fig. 3). Patient 4 was admitted to the clinic with a drop in feed consumption, drop in milk production, high tem- 
perature and generally ill thriftiness and depression. Ultrasonography was performed and fluid, fibrin and purulent material was imaged at 9-10th ICS. Local peritonitis was diagnosed (Fig. 4).

The six healthy cattle had an average cranial duodenum wall thickness of $2.45 \mathrm{~mm}$, an average jejunum wall thickness of $1.90 \mathrm{~mm}$, and an average colon wall thickness of $3.02 \mathrm{~mm}$ (Table 1). The statistical analysis revealed a significant difference between the jejunum and the colon wall thickness $(\mathrm{P}<0.01)$. Of the pathological cases, three out of four had intestines that were thicker than the average value from the healthy cattle (Table 1). The thickest intestines were found in patient 2 suffering from paratuberculosis (Fig. 5, 6, 7).

\section{DISCUSSION}

The proposed abdominal zones were scanned in all healthy cattle. All of the control cattle had their organs within the zones that were proposed. The only pathological case to have their gastrointestinal organs within the proposed abdominal zones was patient 3 that was post abomasopexy surgery. All of the other pathological cases had abdominal organs outside of the proposed zones. Patients with abomasal displacement are characterised by a changed position of the abdominal organs, due to the enlarged and displaced abomasum. The patient in our study suffered from a left displacement of the abomasum that led to displacement of intestines and liver cranially and ventrally in the right half of the abdomen which became "empty" due to displacement of the abomasums [6]. In the patient with paratuberculosis, the ultrasound scanning revealed that the forestomachs and liver were all within the proposed zones. However, the jejunum was located in zone 3 , adjacent to the omasum at the $8-9$ th ICS, instead of zone $6 \mathrm{~B}$ and C. These changes are thought to be due to inflammation within the intestines. This inflammatory process could be responsible for making intestines enlarged and heavier and thus they extended more cranially throughout the abdomen. When the size and position changes of the organs are not very strong, no changes in their location and borderlines can be observed like in the patient with post abomasopexy abscess in the abdominal cavity. However, without ultrasonography the abscess would not have been identified and therefore may not have been treated, which may have caused other systemic effects [4]. Moreover, ultrasound imaging of the abomasum in the post abomasopexy patient revealed inflammation, fibrous tissue and part of the "toggle" fixation from the abomasopexy operation within the parenchyma of the abomasum. All these findings can occur when the fixation of the abomasum is not performed correctly and belong to the most frequent complications of the percutaneous abomasopexy [7]. Pathological processes associated with diffuse peritonitis can also lead to changes in the positions of the abdominal organs. This is due to the changed volume of the organs, as both abomasum and intestines are usually suffering from decreased motility, leading to the accumulation of ingesta and gas within the lumen [3]. Such a situation could be seen in the patient with peritonitis in our study. The abomasum was located more caudally in zone $6 \mathrm{C}$ instead of zone 4 . The abomasum wall had a hyperechogenic appearance and was thicker when compared to the healthy cattle. This was thought to be due to inflammation from the peritonitis. The liver and the cranial duodenum were imaged more cranially at the level of the 9-10th ICS. This was because the left kidney was found to be considerably enlarged, therefore displacing the other organs cranially and ventrally.

The intestinal wall thickness was chosen to measure because it has been proposed to be a potential parameter of intestinal health [3]. The wall of the normal small intestine is 2 to $3 \mathrm{~mm}$ thick and its luminal diameter is 2 to $4 \mathrm{~cm}$ in adult cattle [5]. The mean thickness of the intestinal walls in the six healthy cattle in our study was nearly within this range measured as: $2.45 \mathrm{~mm}$ (cranial duodenum), and $1.90 \mathrm{~mm}$ (jejunum). The mean thickness of the colon wall was thicker $(3.02 \mathrm{~mm})$ in comparison to the small intestine. Even if all the patients in our study suffered from abdominal diseases, only three of them demonstrated thicker intestinal walls than the six healthy cattle scanned. Surprisingly, the animal with the left displacement of the abomasum had thicker intestinal walls than the animal with peritonitis. Thus, individual reaction of the intestinal structures to pathological processes in the abdominal space can be suggested. The thickest intestinal walls when compared to the other pathological cases and the control cattle, was seen in the patient with paratuberculosis. The duodenum wall of this patient measured $9.5 \mathrm{~mm}$, the jejunum measured $4.9 \mathrm{~mm}$ and the colon wall measured as $10.0 \mathrm{~mm}$. This was three to four times thicker than the mean values from the control cattle. This correlates with information stating that 
cattle positive for Mycobacterium avium subsp. Paratuberculosis, have three to four times thicker intestinal walls, especially the jejunum and ileocaecal valve section [1]. There is currently no data using ultrasonography to measure the thickness of the intestinal walls in cattle with intestinal disorders such as paratuberculosis. The only data available for ultrasound diagnosis of the thickness of the intestinal walls due to paratuberculosis is that from goats and camels [10].

In conclusion, trans-abdominal ultrasonography is an ideal non-invasive and economical diagnostic tool for the investigation of the bovine gastrointestinal tract and gastrointestinal disorders. This study has demonstrated the ability of the use of ultrasound to diagnose diseases such as local peritonitis, the presence of intra-abdominal abscesses, and the confirmation of displaced abomasum. Moreover, this technique may be a promising method in the diagnostics of clinical forms of paratuberculosis in cattle.

\section{ACKNOWLEDGEMENT}

This study was supported by the Slovak Research and Development Agency under the contract No. APVV-0701-11.

\section{REFERENCES}

1. Behr, M.A., Collins, D.M., 2001: Paratuberculosis: Organism, Disease, Control. CAB International, Oxfordshire, England, 138-188.
2. Braun, U., 2003: Ultrasonography in gastrointestinal disease in cattle. Vet. J., 166, 112-24.

3. Braun, U., 2009: Ultrasonography of the gastrointestinal tract in cattle. Vet. Clin. N. Am. Food Anim. Pract., 25, 567-590.

4. Braun, U., Iselin, U., Lischer, C., Fluri, E., 1998: Ultrasonographic findings in five cows before and after treatment of reticular abscesses. Vet. Rec., 142, 184-189.

5. Braun, U., Marmier, O., 1995: Ultrasonographic examination of the small intestine of cows. Vet. Rec., 136, 239-44.

6. Dirksen, G., 2006: Krankheiten der Verdauungsorganen und der Bauchwand. In Dirksen, G., Grunder, H. D., Stober, M.: Innere Medizin und Chirurgie des Rindes. 5th edn., MVS Medizinverlage Stuttgart, 357-597.

7. Fubini, S., Divers, J.D., 2008: Noninfectious diseases of the gastrointestinal tract. In Divers, J.D., Peek, S. F. (Eds.): Rebhun's Diseses of Dairy Cattle. Elsevier Inc, St. Louis, 130-200.

8. Mucha, R., Bhide, M.R., Chakurkar, E.B., Novak, M., Mikula, I. Sr., 2009: Tolle-like receptors TLR1, TLR2 and TLR4 gene mutations and natural resistance to Mycobacterium avium subsp. paratuberculosis infection in cattle. Vet. Immunol. Immunopathol., 128, 381-388.

9. Popesko, P., 1992: Splanchnology (In Slovak). In Popesko, P. et al.: Anatómia Hospodárskych Zvierat (Anatomy of Farm Animals), Príroda, Bratislava, 239-379.

10. Tharwat, M., Al-Sobayil, F., Hashad, M., Buczinski, S., 2012: Transabdominal ultrasonographic findings in goats with paratuberculosis. Can. Vet. J., 53, 1063-1070.

Received November 19, 2015 